\title{
Clinical features of brain metastasis from salivary gland tumors
}

\section{Citation}

Venteicher, Andrew S., Brian P. Walcott, Sameer A. Sheth, Matija Snuderl, Anoop P. Patel, William T. Curry, and Brian V. Nahed. 2013. Clinical Features of Brain Metastasis from Salivary Gland Tumors. Journal of Clinical Neuroscience 20, no. 11: 1533-1537. doi:10.1016/ j.jocn.2012.11.024.

\section{Published Version}

doi:10.1016/j.jocn.2012.11.024

\section{Permanent link}

http://nrs.harvard.edu/urn-3:HUL.InstRepos:37034627

\section{Terms of Use}

This article was downloaded from Harvard University's DASH repository, and is made available under the terms and conditions applicable to Other Posted Material, as set forth at http:// nrs.harvard.edu/urn-3:HUL.InstRepos:dash.current.terms-of-use\#LAA

\section{Share Your Story}

The Harvard community has made this article openly available.

Please share how this access benefits you. Submit a story.

\section{Accessibility}




\title{
Clinical features of brain metastasis from salivary gland tumors
}

\author{
Andrew S. Venteicher ${ }^{a}$, Brian P. Walcott ${ }^{a},{ }^{*}$, Sameer A. Sheth ${ }^{\mathrm{a}}$, Matija Snuderl ${ }^{\mathrm{b}}$, Anoop P. \\ Patel $^{\mathrm{a}}$, William T. Curry ${ }^{\mathrm{a}}$, and Brian V. Nahed ${ }^{\mathrm{a}}$ \\ aDepartment of Neurosurgery, Massachusetts General Hospital, Harvard Medical School, 55 Fruit \\ Street, White Building Room 502, Boston, Massachusetts 02114, USA \\ bDepartment of Pathology, Massachusetts General Hospital, Harvard Medical School, Boston, \\ Massachusetts, USA
}

\begin{abstract}
Salivary gland tumors comprise a group of 24 tumor subtypes with a wide range of clinical behaviors and propensities for metastasis. Several prognostic factors have been identified that help predict the development of systemic metastases, most commonly to the lung, liver, or bone. Metastases to the brain are rare. To better understand the behavior of salivary gland tumors that metastasise to the brain, we performed a retrospective cohort analysis on a series of patients to highlight features of their medical and surgical management. From 2007 to 2011, a database of 4117 elective craniotomies were queried at a single institution to identify patients surgically treated for salivary gland metastases to the brain. Three patients were identified. Histologic subtypes included salivary duct carcinoma, poorly differentiated carcinoma, and papillary mucinous adenocarcinoma. They had all undergone previous treatment for their primary malignancy. The mean time to intracranial metastasis was 48 months from initial diagnosis (range, 14-91 months). Treatment for intracranial metastases included surgical resection, whole brain radiation, stereotactic radiosurgery, and chemotherapy. Intracranial metastases from salivary gland tumors are rare, present years after diagnosis of the primary tumor, and are treatable with multimodality therapy.
\end{abstract}

\section{Keywords}

Brain tumor; Metastasis; Parotid; Radiation; Salivary; Submandibular; Surgery

\section{Introduction}

Salivary gland malignancies comprise a heterogeneous group of tumors with different propensities for metastasis. Salivary gland malignancies have an estimated incidence of 0.52.5 per 100,000 people. ${ }^{1-3}$ In the US, incidence of salivary gland cancer has increased significantly towards the end of the 1990 s, from $6.3 \%$ in $1974-1976$ to $8.1 \%$ of all head and neck cancers in 1998-1999. ${ }^{4}$ Most arise from the parotid glands (70-80\%), with the remainder arising from submandibular gland $(10 \%)$ or sublingual and minor salivary glands

\footnotetext{
(C) 2013 Elsevier Ltd. All rights reserved.

*Corresponding author. Tel.: +1 617 726 2000; fax: +1 617643 4113. brian.walcott@mgh.harvard.edu (B. Walcott).

Conflicts of Interest/Disclosures

The authors declare that they have no financial or other conflicts of interest in relation to this research and its publication.

Publisher's Disclaimer: This is a PDF file of an unedited manuscript that has been accepted for publication. As a service to our customers we are providing this early version of the manuscript. The manuscript will undergo copyediting, typesetting, and review of the resulting proof before it is published in its final citable form. Please note that during the production process errors may be discovered which could affect the content, and all legal disclaimers that apply to the journal pertain.
} 
$(5 \%){ }^{3}$ Survival in adults is approximately $83 \%$ at 1 year, $69 \%$ at 3 years and $65 \%$ at 5 years. Prognostic factors include sex and age. Women typically have higher survival rates than men ( $72 \%$ versus $58 \%$ ), and the 5 year survival is higher among patients aged $15-45$ versus those older than 75 years ( $87 \%$ and $59 \%$, respectively). ${ }^{5}$

Since the majority of patients have long survival times following initial diagnosis, the development of metastatic disease is relatively common. For example, high-grade salivary ductal carcinoma eventually metastasizes in $46 \%$ of patients, often with indolent courses. ${ }^{6}$

The most common sites for metastases are lung $(80 \%)$, bone (15\%), and liver and other sites $(5 \%)$. Metastases to the brain are very rare with only limited data available in the literature. ${ }^{7-15}$ Surgery and radiation are traditionally the mainstays for therapy both for primary as well as metastatic lesions. We report a series of salivary gland malignancy with metastases to the brain to highlight this rare clinical entity and review the medical and surgical management.

\section{Methods}

Following institutional board approval, a retrospective analysis was performed during the period of 2007-2011 at a single, quaternary-level care neurosurgical center. Four thousand, one hundred and seventeen craniotomies were identified during the period that were subsequently queried for histopathology consistent with salivary gland metastases. Each case was reviewed by a neuropathologist (MS) and diagnosis was confirmed. The electronic medical record was queried for treatment history including clinic notes, hospital notes, operative notes, radiation treatment dosimetry plans, and neuroimaging.

\section{Results}

\subsection{Patient 1}

A 60-year-old woman presented with a lump under the angle of her right mandible. She underwent resection and neck dissection and was found to have a primary $1.5 \mathrm{~cm}$ salivary duct carcinoma of the right submandibular gland with vascular and perineural invasion. Metastases were found in three of 19 regional lymph nodes. Immunohistochemistry was positive for amplification of HER2/Neu. Postoperatively, she completed a concurrent course of cisplatin and radiotherapy. Follow-up surveillance CT scans performed 6 months later demonstrated multiple pulmonary nodules consistent with metastatic disease. Two years following the original diagnosis, MRI of the spine demonstrated vertebral body metastases from T8 to T12 causing lower thoracic pain that was palliated with radiotherapy ( $35 \mathrm{~Gy}$ ) and concurrent chemotherapy (taxol and trastuzumab).

She continued on trastuzumab monotherapy for 1 year without symptoms until she presented with unsteady gait. Brain MRI revealed a contrast enhancing $1.5 \mathrm{~cm}$ right cerebellar mass (Fig. 1a-c), as well as right parietal and left frontal masses. She underwent a suboccipital craniotomy to resect her cerebellar mass, followed by 35 Gy whole brain radiation administered in 14 fractions, followed by a boost of $18 \mathrm{~Gy}$ with stereotactic proton radiosurgery to the right parietal lesion. Four years following the initial diagnosis, she had a generalized seizure that began with left arm and leg twitching. A CT scan of the brain demonstrated hemorrhage into the right parietal lesion (she was being treated with low molecular weight heparin at the time for an incidentally discovered pulmonary embolism). Anticoagulation was discontinued and an inferior vena cava filter was placed. She underwent right parietal craniotomy for tumor resection. Histopathological review confirmed an adenocarcinoma with extensive necrosis consistent with metastasis from her salivary gland tumor (Fig. 1d, e). Her postoperative course was complicated by intermittent seizure activity despite high-dose levetireacetam. 
Unfortunately, widespread brain disease progression was found on routine surveillance imaging 3 months after the second craniotomy. After discussion with the patient and her family about her goals of care, she was transitioned to hospice care.

\subsection{Patient 2}

A 52-year-old woman presented with neck swelling and progressive trismus over 3 months. MRI of the head and neck revealed a deep parotid mass measuring $1.4 \mathrm{~cm}$, with involvement of the mandible and pterygoids at the skull base. Positron emission tomography demonstrated intense uptake of the parotid mass and a level II neck lymph node. She underwent open biopsy for definitive diagnosis, which showed a poorly differentiated carcinoma that was positive for keratin staining but negative for S100. Due to the unresectability of the primary lesion, she underwent concurrent chemoradiation with carboplatin and taxol. The left neck field received 60 Gy over 3 months with a $10 \mathrm{~Gy}$ boost to the primary lesion and involved lymph node. One year later, routine surveillance MRI of the neck revealed an asymptomatic ring-enhancing left temporal lobe lesion (Fig. 2a-c). She underwent left temporal craniotomy for surgical resection of the enhancing mass. Pathologic analysis of the temporal lobe specimen demonstrated poorly differentiated carcinoma with similar morphological and immunohistochemical features to the parotid primary tumor (Fig. $2 \mathrm{~d}, \mathrm{e})$. She was subsequently treated with stereotactic radiosurgery of $15 \mathrm{~Gy}$ to the residual disease in the left temporal resection cavity. Surveillance imaging of the parotid and temporal lesions have shown a good response thus far. The most recent brain MRI a year following the craniotomy demonstrated a slight increase in size of the remaining enhancing lesion in the left temporal lobe.

\subsection{Patient 3}

A 48-year-old man presented with a several year history of gradually enlarging mass in the posterior mouth. A biopsy demonstrated papillary mucinous adenocarcinoma arising from a minor salivary gland. Staging CT scans and MRI demonstrated the primary mass with extension to the soft palate, anterior pillar, and retromolar trigone but no lymphadenopathy. He was treated by surgical resection and postoperative radiotherapy.

Surveillance imaging 1 year later identified bilateral pulmonary metastases that were managed by surgical resection and radiofrequency ablation. Pathology demonstrated a mucinous adenocarcinoma, which was progesterone receptor positive, estrogen receptor negative tumor without over-expression of HER2/Neu. Another year later, his pulmonary lesions had progressed and capacitabine chemotherapy was started and led to disease stability. However, 3 years following the initial diagnosis, he was found to have distant metastases to the calf and the chest wall. The calf lesion was resected with close margins, but later recurred and was treated with radiotherapy. Gemcitobine chemotherapy had little perceived effect and he was enrolled in a clinical trial for small molecule chemotherapy targeting phosphatidyl inositol kinase mutated tumors.

Unfortunately, 4 years following initial diagnoisis, he developed gait instability and dizziness. A brain MRI revealed four intracranial lesions, highlighted by a dominant $3.2 \mathrm{~cm}$ left cerebellar mass (Fig. 3a-d). He underwent craniotomy for resection of the cerebellar mass, and histopathology was consistent with metastasis of the salivary gland primary tumor with extensive mucin production (Fig. 3e, f). He then underwent 14 fractions of whole brain radiation totaling $35 \mathrm{~Gy}$. He is currently doing well at his 6 month follow-up with intermittent headaches. He is being followed with surveillance imaging. 


\section{Discussion}

Salivary gland tumors comprise 24 different histologic subtypes, as classified by the World Health Organisation histological classification published in 2005. ${ }^{16}$ Aggressive subtypes include anaplastic carcinoma, squamous cell carcinoma, carcinoma in pleomorphic adenoma, high-grade mucoepidermoid tumors, salivary duct carcinoma, oncocytic carcinoma, and large cell carcinoma. ${ }^{6}$ Prognosis and propensity for distant metastases correlates with histology, grade, facial nerve paralysis for parotid tumors, lymphovascular or perineural invasion, and HER2/Neu status. ${ }^{6}$ It should be noted that intracranial direct extension of the tumor is not the same as hematogenous metastatic spread. ${ }^{17}$

This series highlights prognostic features that correlate with systemic metastasis of salivary gland tumors and management strategy for brain metastases. In the patients described here, each had a distinct histologic subtype which has previously been described as having aggressive clinical behavior. In addition, histopathologic features including HER2/Neu amplification, which is seen in $57-73 \%$ of salivary gland tumors, correlates with poorer prognosis. ${ }^{18,19}$ Patient 1 had evidence of lymphvascular/perineural involvement and HER2/ Neu amplication on histologic analysis of the primary tumor. Patient 2 had a high-grade and unresectable primary tumor, and as such was treated with radiation alone. Patient 3 had regional extension of the primary tumor at the time of initial resection despite normal HER2/ Neu expression, and subsequently had a long interval between diagnosis of the primary tumor and the development of symptomatic brain metastases. These characteristics of aggressive salivary gland tumors should prompt close surveillance of these patients for the development of systemic and central nervous system metastases.

Brain metastases develop as late sequelae in patients with salivary gland malignancy. Two patients had symptomatic brain lesions, while one patient had an incidentally discovered asymptomatic brain metastasis. Symptomatic lesions presented approximately 3 and 7 years after the primary tumor was diagnosed (Table 1). Management of these brain metastases for salivary gland tumors was essentially the same as the general management for brain metastases for other tumor types (Table 1). Symptomatic lesions are resected if the tumor location is favorable. The evidence for this is based on the time-tested evidence reported by Patchell et al. that patients with a single metastasis who are treated by surgical resection plus radiotherapy live longer, have fewer local recurrences, and have an improved quality of life compared with radiation therapy alone. ${ }^{20}$

Radiotherapy, either to the tumor bed via stereotactic radiosurgery (in the case of single brain metastasis) and/or whole brain radiation (in the case of multiple lesions), is then used postoperatively. This highlights a current area of study: the efficacy of stereotactic radiosurgery for the treatment of brain metastasis following surgical resection. It is well known that whole brain radiotherapy can have detrimental neurocognitive effects, making localized therapy such as stereotactic radiosurgery a potentially more attractive alternative. However, in a prospective radomized trial of brain metastases treated with either whole brain radiotherapy or whole brain radiotherapy plus stereotactic radiosurgery, control of the brain tumor was found to be the most important factor for stabilizing neurocognitive function. Even so, the long-term effects of whole brain radiation are certainly not negligible. ${ }^{21}$ Directly addressing this question is a phase III trial of post-surgical stereotactic radiosurgery compared with whole brain radiotherapy for resected metastatic brain disease (ClinicalTrials. gov identifier NCT01372774). Additionally, a dose escalation phase II clinical trial is currently underway to identify the maximally safe dose of stereotactic radiosurgery that can be administered following surgical resection of brain metastases in an attempt to improve local control by increasing radiation dosage (ClinicalTrials. gov identifier NCT00587964). 
The scarcity of salivary gland tumors with intracranial metastases makes clinical trials of chemotherapy difficult. Several agents have shown benefit in non-randomized studies, with carboplatin and paclitaxel being the most frequently used. ${ }^{22,23}$ Also, trastuzumab has been shown to have low activity levels in HER2/Neu overexpressing salivary gland tumors in a phase II study. ${ }^{24}$ Small molecules targeting cancers with distinct molecular profiles, such as the case in Patient 3, are currently being evaluated (ClinicalTrials. gov identifier:

NCT01390818).

\section{Conclusions}

Salivary gland malignancies have a protracted course which often results in systemic metastasis. The primary tumor is most often treated with surgical resection and postoperative radiation to the tumor bed. Systemic metastases most often affect the lungs and require the addition of chemotherapy. As surgical and chemoradiation therapies have led to increased control of primary and systemic disease, the number of patients displaying brain metastases may continue to rise as patients live longer. When brain metastases grow or are symptomatic, then surgical resection is indicated. Postoperative radiation, either with stereotactic radiosurgery to the tumor bed or whole brain radiation in the case of multiple brain metastases, is used to limit recurrence. While not yet a main aspect of the treatment of central nervous system metastasis, chemotherapy with activity towards salivary gland tumors with central nervous system penetration will be an important addition to the future armamentarium of adjunctive therapies. Since many salivary gland tumors grow relatively slowly, this strategy of multimodality therapy may lead to lasting control of malignant disease.

\section{References}

1. Parkin DMWS, Ferlay J, Teppo L, Thomas DB. Cancer incidence in five continents. IARC Scientific Publications No 155. 2002; VIII

2. Spiro RH. Salivary neoplasms: overview of a 35-year experience with 2,807 patients. Head Neck Surg. 1986; 8:177-184. [PubMed: 3744850]

3. Ellington CL, Goodman M, Kono SA, Grist W, Wadsworth T, Chen AY, et al. Adenoid cystic carcinoma of the head and neck: Incidence and survival trends based on 1973-2007 Surveillance, Epidemiology, and End Results data. Cancer. 2012

4. Carvalho AL, Nishimoto IN, Califano JA, Kowalski LP. Trends in incidence and prognosis for head and neck cancer in the United States: a site-specific analysis of the SEER database. Int J Cancer. 2005; 114:806-816. [PubMed: 15609302]

5. Berrino F, De Angelis R, Sant M, Rosso S, Bielska-Lasota M, Coebergh JW, et al. Survival for eight major cancers and all cancers combined for European adults diagnosed in 1995-99: results of the EUROCARE-4 study. Lancet Oncol. 2007; 8:773-783. [PubMed: 17714991]

6. Guzzo M, Locati LD, Prott FJ, Gatta G, McGurk M, Licitra L. Major and minor salivary gland tumors. Crit Rev Oncol Hematol. 2010; 74:134-148. [PubMed: 19939701]

7. Cui R, Cheng X, Li F, Zhuang H. Rare cerebral and pulmonary metastases from low-grade basal cell adenocarcinoma of the parotid gland. Clin Nucl Med. 2011; 36:1124-1126. [PubMed: 22064088]

8. Dawson SJ, Murray RM, Rischin D. Hypocalcemia associated with bone metastases in a patient with salivary-gland carcinoma. Nat Clin Pract Oncol. 2006; 3:104-107. [PubMed: 16462851]

9. Dequanter D, Andry G, Lothaire P, Larsimont D, Deraemaecker R. Wide localized excision and reconstruction for minor salivary gland tumours. B-Ent. 2005; 1:187-190. [PubMed: 16429751]

10. Grisanti S, Amoroso V, Buglione M, Rosati A, Gatta R, Pizzocaro C, et al. Cetuximab in the treatment of metastatic mucoepidermoid carcinoma of the salivary glands: a case report and review of literature. J Med Case Reports. 2008; 2:320.

11. Kikuchi Y, Hirota M, Iwai T, Aoki S, Chikumaru H, Kawabe R, et al. Salivary duct carcinoma in the mandible: a case report. Oral Surg Oral Med Oral Pathol Oral Radiol Endod. 2007; 103:e4146. [PubMed: 17321438] 
12. Pacheco-Ojeda L, Domeisen H, Narvaez M, Tixi R, Vivar N. Malignant salivary gland tumors in Quito, Ecuador. ORL J Otorhinolaryngol Relat Spec. 2000; 62:296-302. [PubMed: 11054011]

13. Pompili A, Carapella CM, Cattani F, Fabi A, Giannarelli D, Giovannetti M, et al. Metastases to the cerebellum. Results and prognostic factors in a consecutive series of 44 operated patients. $\mathrm{J}$ Neurooncol. 2008; 88:331-337. [PubMed: 18392776]

14. van der Wal JE, Becking AG, Snow GB, van der Waal I. Distant metastases of adenoid cystic carcinoma of the salivary glands and the value of diagnostic examinations during follow-up. Head Neck. 2002; 24:779-783. [PubMed: 12203804]

15. Yamamoto H, Uryu H, Segawa Y, Tsuneyoshi M. Aggressive invasive micropapillary salivary duct carcinoma of the parotid gland. Pathol Int. 2008; 58:322-326. [PubMed: 18429833]

16. Barnes, L.; Eveson, JW.; Reichart, P.; Sidransky, D. World Health Organization classification of tumors. Lyon: IARC Press; 2005.

17. Maiuri F, Gangemi M, Giamundo A, Mariniello G, Colella A, Vergara P, et al. Intracranial extension of salivary gland tumors. Clin Neuropathol. 2010; 29:9-13. [PubMed: 20040327]

18. Dagrada GP, Negri T, Tamborini E, Pierotti MA, Pilotti S. Expression of HER-2/neu gene and protein in salivary duct carcinomas of parotid gland as revealed by fluorescence in-situ hybridization and immunohistochemistry. Histopathology. 2004; 44:301-302. [PubMed: 14987238]

19. Skalova A, Starek I, Vanecek T, Kucerova V, Plank L, Szepe P, et al. Expression of HER-2/neu gene and protein in salivary duct carcinomas of parotid gland as revealed by fluorescence in-situ hybridization and immunohistochemistry. Histopathology. 2003; 42:348-356. [PubMed: 12653946]

20. Patchell RA, Tibbs PA, Walsh JW, Dempsey RJ, Maruyama Y, Kryscio RJ, et al. A randomized trial of surgery in the treatment of single metastases to the brain. N Engl J Med. 1990; 322:494500. [PubMed: 2405271]

21. Aoyama H, Tago M, Kato N, Toyoda T, Kenjyo M, Hirota S, et al. Neurocognitive function of patients with brain metastasis who received either whole brain radiotherapy plus stereotactic radiosurgery or radiosurgery alone. Int J Radiat Oncol Biol Phys. 2007; 68:1388-1395. [PubMed: 17674975]

22. Kaplan MJ, Johns ME, Cantrell RW. Chemotherapy for salivary gland cancer. Otolaryngol Head Neck Surg. 1986; 95:165-170. [PubMed: 3035459]

23. Schoenfeld JD, Sher DJ, Norris CM Jr, Haddad RI, Posner MR, Balboni TA, et al. Salivary gland tumors treated with adjuvant intensity-modulated radiotherapy with or without concurrent chemotherapy. Int J Radiat Oncol Biol Phys. 2012; 82:308-314. [PubMed: 21075557]

24. Haddad R, Colevas AD, Krane JF, Cooper D, Glisson B, Amrein PC, et al. Herceptin in patients with advanced or metastatic salivary gland carcinomas. A phase II study. Oral Oncol. 2003; 39:724-727. [PubMed: 12907212] 

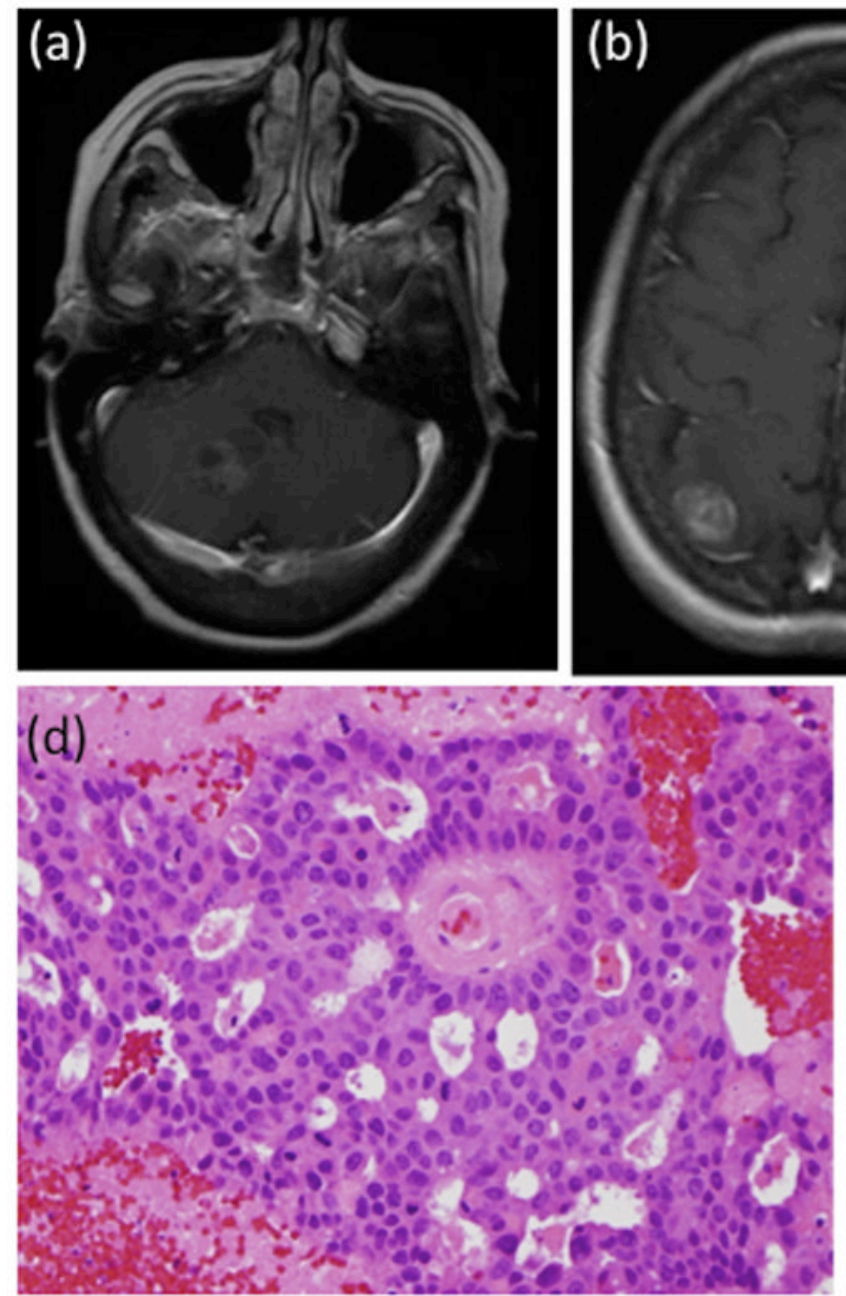
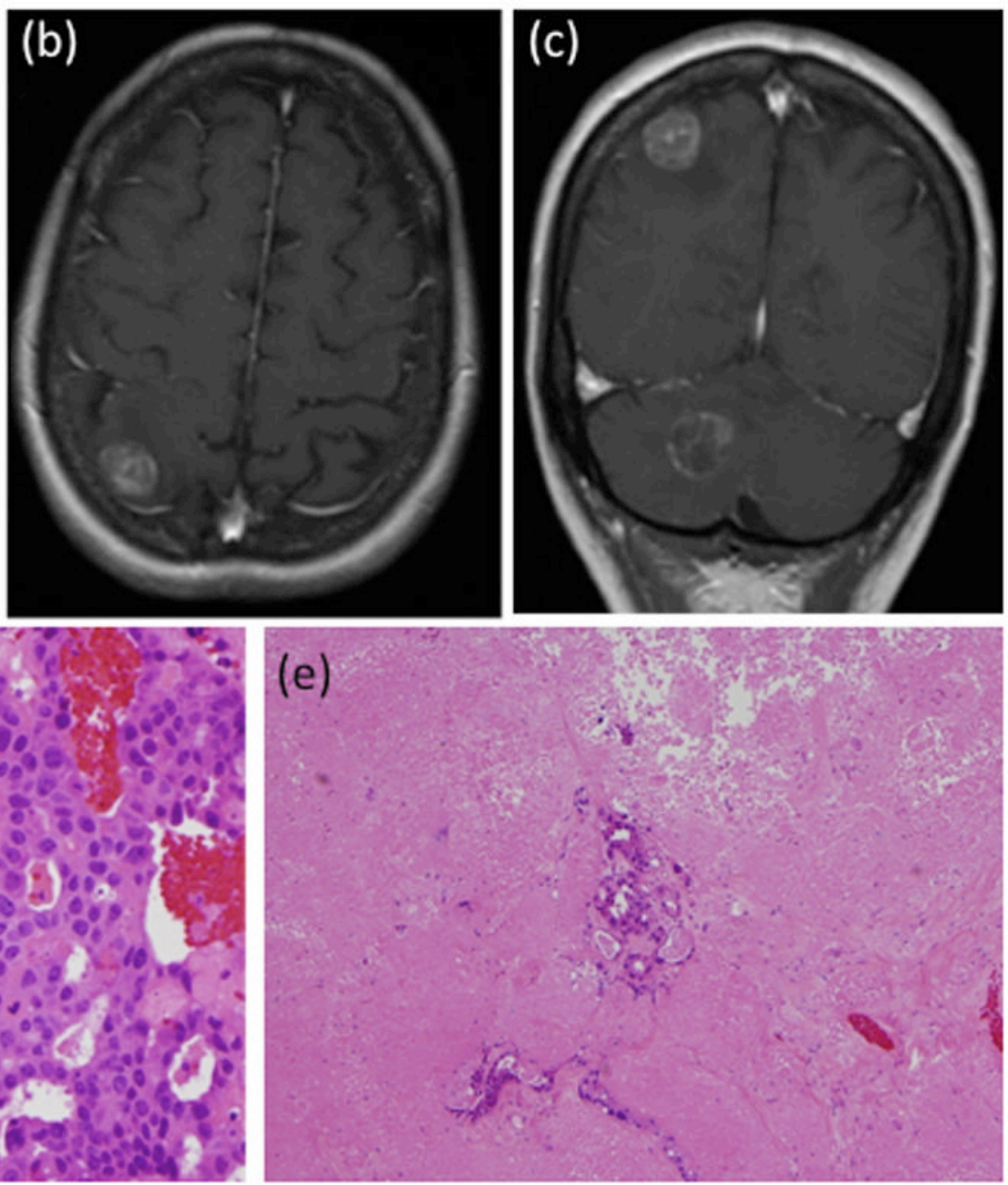

Fig. 1.

Patient 1 with metastasis from salivary duct carcinoma. Post-contrast MRI of (a) axial section showing the right cerebellar lesion, (b) axial section showing the right parietal lesion, (c) coronal section showing both the right cerebellar and parietal lesions.

Histopathology samples showing (d) adenocarcinoma with extensive necrosis (original magnification $\times 400$ ), with (e) scattered glands present in otherwise entirely necrotic background (original magnification $\times 100$ ). 

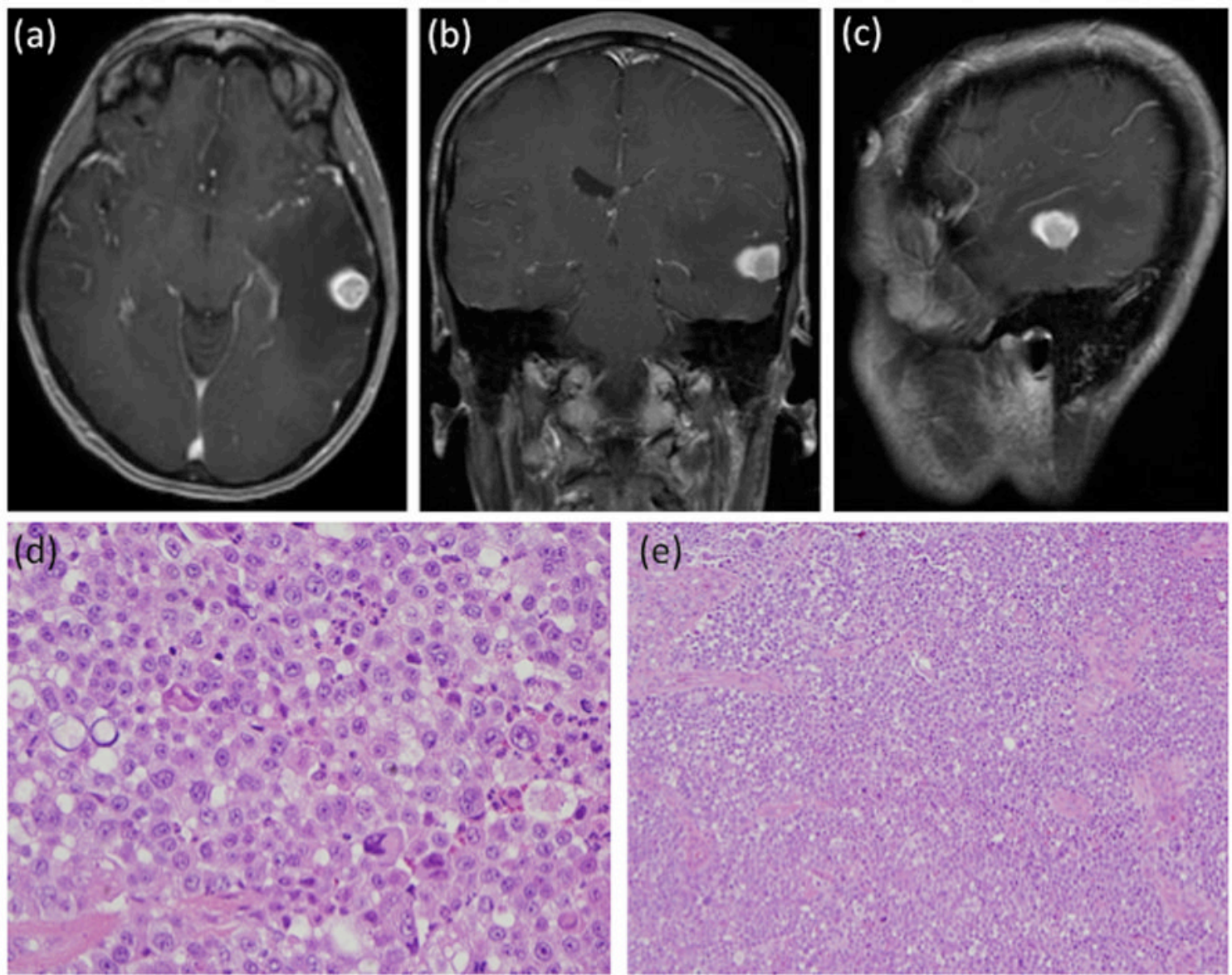

Fig. 2.

Patient 2 with metastasis from poorly differentiated carcinoma. Post-contrast MRI of (a) axial section showing the left temporal lesion, (b) coronal section showing the left temporal lesion, and (c) saggital section showing the left temporal lesion. Histopathology samples showing (d) poorly differentiated cells with large nuclei and prominent nucleoli at highpower view (original magnification $\times 400$ ), and (e) sheets of cells without gland formation (original magnification $\times 100$ ). 

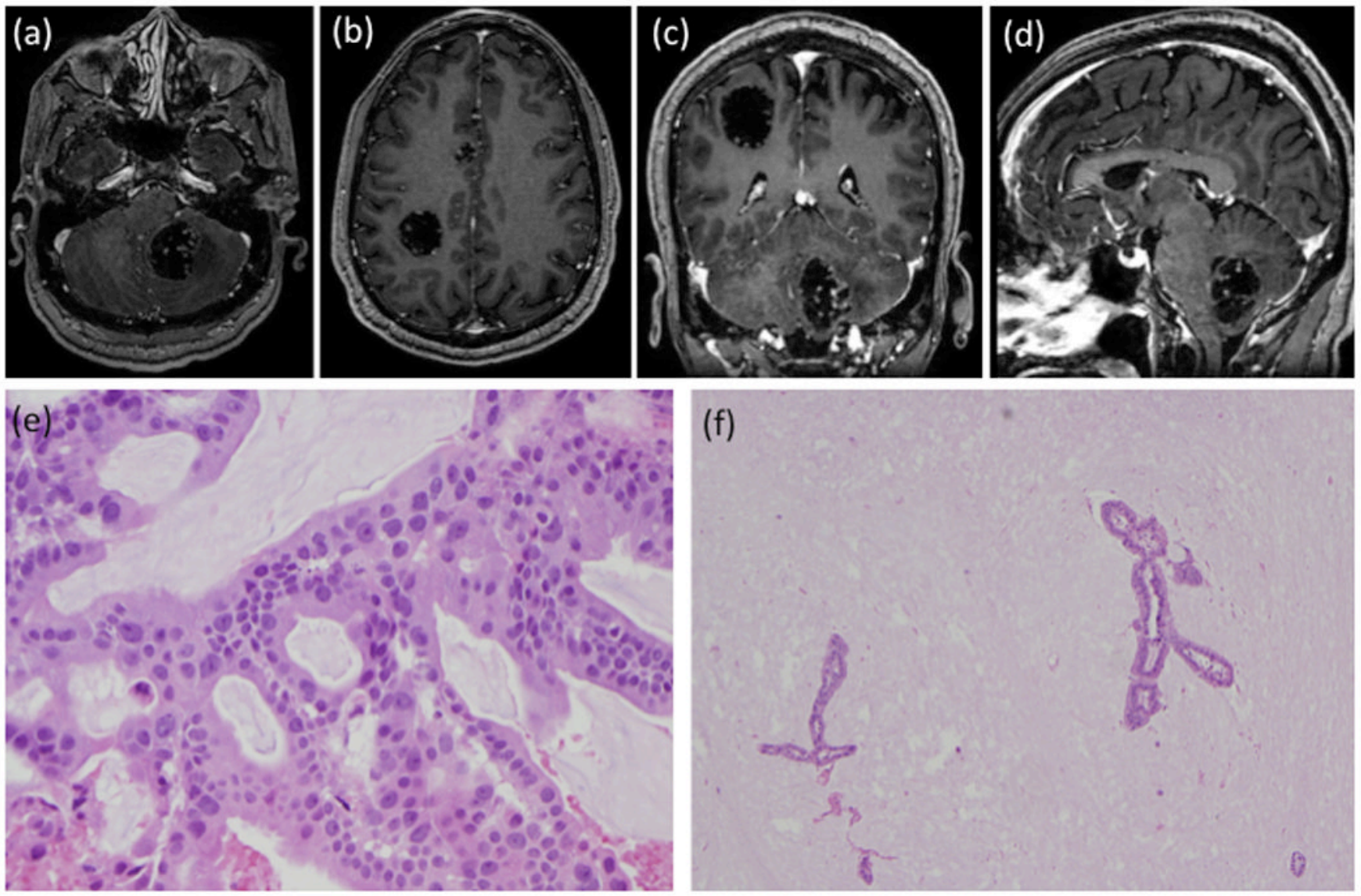

Fig. 3.

Patient 3 with metastasis from papillary mucinous adenocarcinoma. Post-contrast MRI of (a) axial section showing the left cerebellar lesion, (b) axial section showing the right parietal and cingulate lesions, (c) coronal section showing the right parietal and left cerebellar lesions, and (d) saggital section showing the left cerebellar lesion. Histopathology samples showing (e) adenocarcinoma with abundant mucin production (original magnification $\times 400$ ), with $(\mathbf{f})$ occasional glands floating in pools of mucin (original magnification $\times 100$ ). 


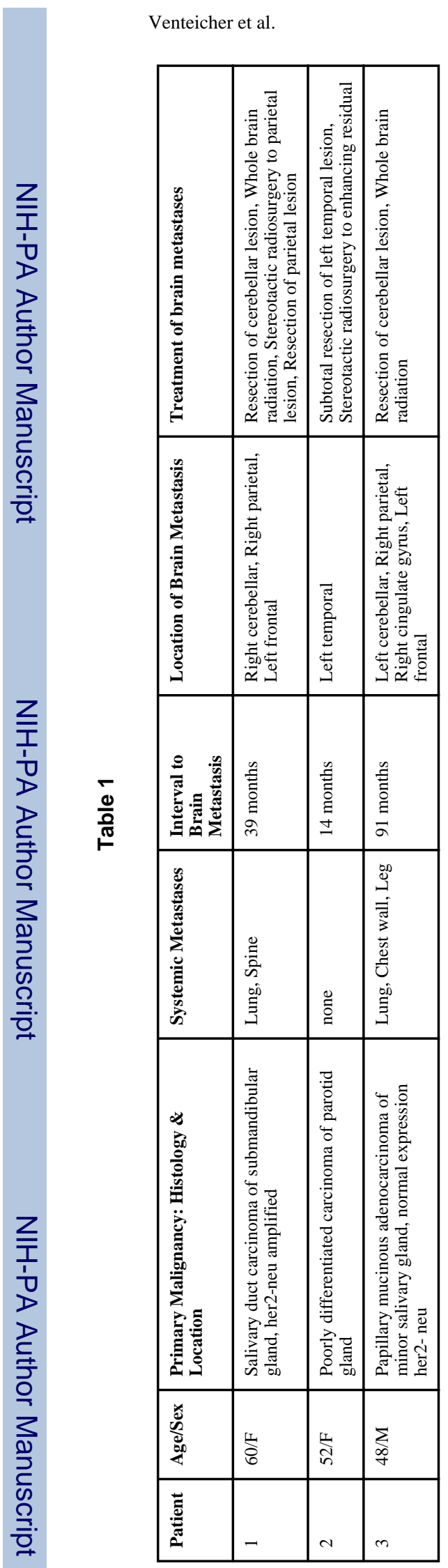

Page 10

\begin{tabular}{|c|c|c|c|}
\hline 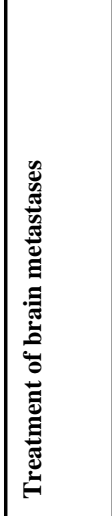 & 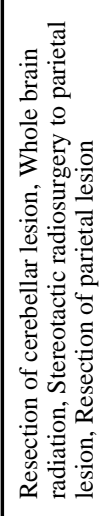 & 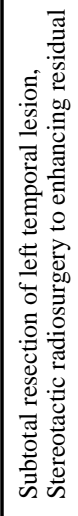 & 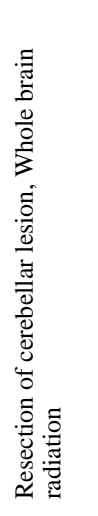 \\
\hline 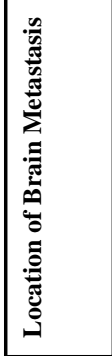 & 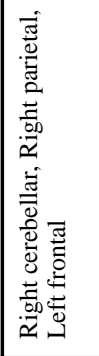 & 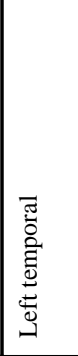 & 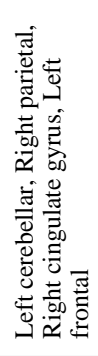 \\
\hline 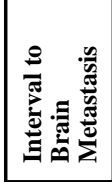 & 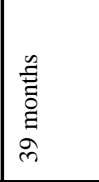 & 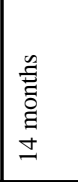 & 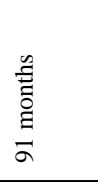 \\
\hline 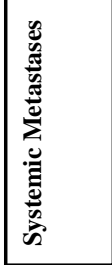 & 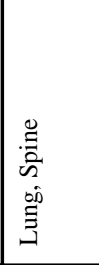 & $\stackrel{\Xi}{\Xi}$ & 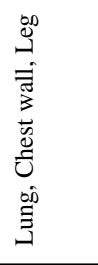 \\
\hline 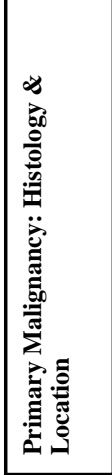 & 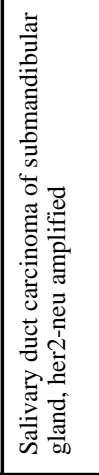 & 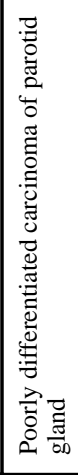 & 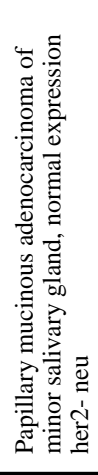 \\
\hline 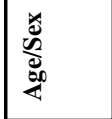 & 音 & 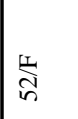 & $\underset{\substack{\infty \\
+}}{\sum}$ \\
\hline 䔍 & - & & \\
\hline
\end{tabular}

J Clin Neurosci. Author manuscript; available in PMC 2014 November 01. 